\title{
Desenvolvimento e avaliação do desempenho de uma semeadora puncionadora para plantio direto de milho ${ }^{1}$
}

\author{
D ouglas R. Frabetti ${ }^{2}$, Ricardo C. Resende ${ }^{3}$, D aniel M. Q ueiroz ${ }^{3}$, \\ $H$ aroldo C. Fernandes ${ }^{3} \&$ Caetano M. Solza ${ }^{4}$
}

\begin{abstract}
RESU MO
Realizou-se este trabalho com o objetivo de desenvolver uma semeadora pontual para o semeio de milho em sistema de plantio direto e avaliar seu sistema de dosagem e distribuição de sementes. Primeiro, elaborou-se uma lista de requisitos os quais a máquina deveria atender; depois, foi feito o projeto conceitual do corpo da máquina e, em seguida, o projeto detalhado de todas as partes e conjuntos, para posterior construção do protótipo. Em bancada de ensaio avaliou-se o desempenho do sistema dosador e distribuidor de sementes, em relação à variação da velocidade e da quantidade de punções utilizada. 0 delineamento experimental foi em blocos casualizados arranjados em parcelas subdivididas com a parcela principal composta por 6, 9 e 12 punções e a subparcela sendo quatro rotações da roda dosadora correspondentes às velocidades de deslocamento de 4, 6, 8 e $10 \mathrm{~km} \mathrm{~h}^{-1}$. De modo geral, tanto o aumento da velocidade como do número de punções nas rodas, diminuiu o número de duplas e aumentou o número de faltas, porém a diminuição do número de duplas não foi significativo quanto ao aumento do número de faltas. A semeadora exerceu desempenho satisfatório, com média geral do número de normais de $91 \%$.
\end{abstract}

Palavra-chave: semear, espaçamento entre sementes, projeto de máquinas

\section{Development and evaluation performance of a punch planter for direct sowing of corn}

\begin{abstract}
The present work was accomplished to develop a punch planter to sow corn seeds in no-tillage system, and also to evaluate the performance of its seed metering and delivery systems. First of all, a requirement list was established, that the machine would have to attend. Next, the conceptual and the embodiment designs of the machine was made. Then, the detailed design of all machine parts was made and a prototype was constructed. In a testing bench the performance of the seed metering unit and its seed delivery system was assessed in relation to the punch wheel speed and the quantity of punches on the wheel. The statistical design was in random blocks arranged in sub-divided plots with the main plot made of 6, 9 and 12 punches and the sub-plot made of four rotational speeds of the punch wheel, corresponding to the travel speeds of $4,6,8$ and $10 \mathrm{~km} \mathrm{~h}^{-1}$. Generally, the increase in velocity and the increase in the number of punches in the punch wheel decreased the number of doubles and increased the number of missing seeds; however the decrease in number of doubles was not significant compared to the increase in the number of errors. The punch planter had a satisfactory performance, with a global mean of $91 \%$ for normal seed selection and delivery.
\end{abstract}

Key words: plant, seed spacing, machine design

\footnotetext{
${ }_{1}^{1}$ Parte da Dissertação de Mestrado, apresentada pelo primeiro autor à U niversidade Federal de Viçosa (UFV)

2 M BI/CTBE. CEP 13083-970, Campinas, SP. Fone: (19) 3518-3126. E-mail: douglas.frabetti@bioetanol.org.br

${ }_{3}^{3}$ DEA/UFV. CEP 36571-000, Viçosa, MG. Fone: (31) 3899-2729. E-mail: ricardocapucio@ufv.br; haroldo@ufv.br; queiroz@ufv.br

${ }^{4}$ DFT/U FV. Fone: (31) 3899-2613. E-mail: cmsouza@ufv.br
} 


\section{INTRODUÇÃO}

As semeadoras convencionais utilizadas para o semeio de milho apresentam problemas na uniformidade de distribuição das sementes na linha de semeadura, devido a rebotes das sementes no duto de distribuição e seu rolamento no sulco, principalmente quando realizam o trabalho a velocidades elevadas, como contatado por Kurachi et al. (1989), Mahl et al. (2004) e Garcia et al. (2006).

A distribuição desuniforme entre plantas é fator prejudicial para a produtividade da cultura do milho, em virtude da concorrência entre plantas pela interceptação da radiação solar (Palhares, 2003).

Pereira et al. (2008), analisando a influência do espaçamento e a população de milho híbrido FORT e AGN 30A00, com distância entre linhas de semeadura de 0,80 e $0,40 \mathrm{~m}$ e submetidos às populações de 60.000 e 70.000 plantas ha $^{-1}$, concluíram que a redução do espaçamento e o aumento da densidade de plantas não proporcionaram aumento da produtividade; entretanto, a combinação da redução no espaçamento com o aumento na população de plantas, resultou em incremento significativo na produtividade de grãos do híbrido FORT.

A força de tração necessária para semear em sulcos em sistema de plantio direto é maior que no convencional e o corte da cobertura de palha nem sempre é eficiente, podendo causar embuchamento e deposição das sementes sobre a palha. A semeadura pontual revolve menos o solo e, consequentemente, se necessita de menos força de tração; além disso, as punções podem perfurar a cobertura de palha com mais facilidade que os sulcadores, depositando as sementes em contato direto com o solo.

Aratani et al. (2006), avaliando o desempenho quanto ao embuchamento e à qualidade da semeadura entre semeadorasadubadoras original e com modificações mecânicas do sistema de corte de palha e haste sulcadora, em solo muito argiloso e sob grande quantidade de palha do milho safrinha intacta, concluíram que o sistema modificado proporcionou menor número de paradas do conjunto trator-semeadora, em função de embuchamento porém as paradas ainda ocorriam. O desempenho das duas semeadoras-adubadoras avaliadas não foi satisfatório quanto à largura de revolvimento do solo e à uniformidade da profundidade de deposição da semente.

Para solucionar os problemas encontrados na semeadura em sulco, há mais de quatro décadas vários pesquisadores, dentre eles: Jafari \& Fornstrom (1972), Heinemann Júnior et al. (1973), Adekoya \& Buchele (1987), Bonnin (2000), Molin et al. (1998) e Resende (2002), desenvolveram máquinas para fazer a semeadura em covas equidistantes; entretanto, ainda não existe no mercado uma solução confiável, devido às dificuldades encontradas para transferir as sementes do dosador para dentro das covas, a fim de evitar o entupimento das punções e para operar em velocidades elevadas; em contrapartida, algumas máquinas desenvolvidas eram muito complexas.

Tendo em vista as melhorias proporcionadas pelo sistema de semeadura por covas, o presente trabalho teve como objetivo geral o desenvolvimento de tecnologia para o semeio de milho em covas sob sistema de plantio direto e, como objetivos específicos, desenvolver um protótipo de uma semeadora puncionadora para semeadura direta de milho e avaliar a influência da velocidade de operação do protótipo da semeadora na dosagem e distribuição de sementes.

\section{Material E MÉTODOS}

\section{Projeto e construção}

A semeadora foi desenvolvida, construída e avaliada no Departamento de Engenharia Agrícola (DEA), da Universidade Federal de Viçosa (UFV); suas construção e avaliação ocorreram no Laboratório de Mecanização Agrícola do DEA/UFV.

Nesta fase utilizou-se a metodologia de projeto proposta por Pahl \& Beitz (1996), seguindo o fluxograma da Figura 1.

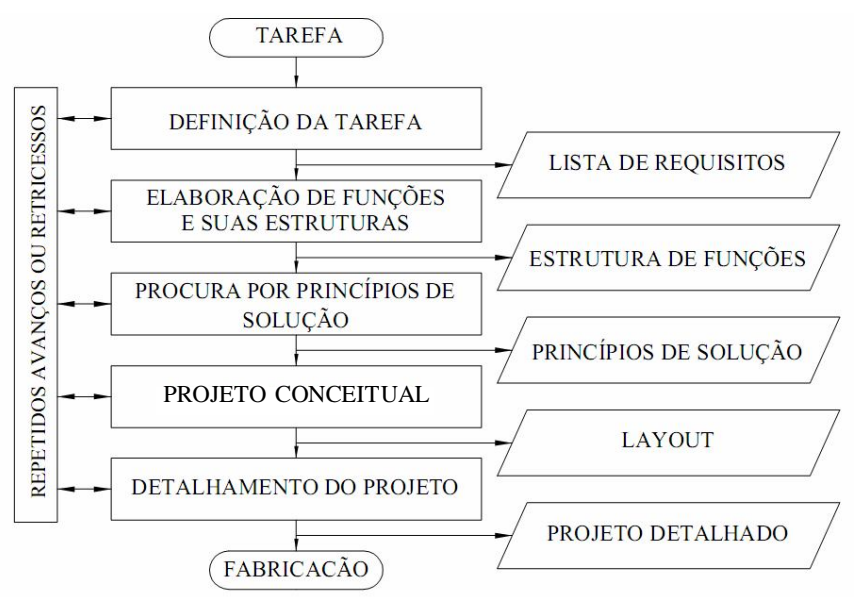

Figura 1. Fluxograma para desenvolvimento do projeto, segundo Pahl \& Beitz (1996)

Seguindo as fazer do projeto, iniciou-se com o estabelecimento e detalhamento das tarefas da semeadora levantando-se os requisitos de projeto dos quais uma semeadora de precisão precisaria atender para realizar a semeadura direta de milho na palha; também foram consideradas as principais restrições envolvidas na solução do problema. Com as definições das tarefas e os requisito do projeto, estabelecendo-se a estrutura de funções que a máquina deveria realizar e procurou-se por princípios de solução para atender todas as funções; o resultado desta fase foi o conceito básico da máquina, ou seja, a definição dos princípios de funcionamento de todos os sistemas da semeadora. Partindo do conceito da máquina, definiram-se o layout da semeadora, a forma, as principais dimensões e os arranjos dos componentes essenciais e da seleção das peças que seriam adquiridas. $\mathrm{O}$ resultado final desta etapa foi, basicamente, o layout do protótipo da semeadora puncionadora e a forma dos componentes. $\mathrm{Na}$ fase de detalhamento do projeto foram preparados os desenhos detalhados das peças que seriam fabricados, definindo todas as suas dimensões e selecionados os materiais de fabricação. Desenhos de montagem de semeadora, como um todo, bem como de alguns subsistemas, também foram elaborados. Os modelos sólidos e desenhos bidimensionais das partes do protótipo foram realizados em um 
programa computacional de CAD (Computer Aided Design) também utilizado para montar um protótipo virtual tridimensional da semeadora e fazer simulações dos movimentos dos componentes. Partiu-se dos desenhos de fabricação da máquina para construção de um protótipo, o qual foi construído utilizando-se máquinas e equipamentos convencionais de ferramentaria tais como torno mecânico, furadora, dobradora de chapas e torno de mesa, dentre outros; após a construção as peças foram pintadas e posteriormente montadas, resultando em um protótipo de semeadora puncionadora.

\section{Avaliação da máquina}

Avaliou-se, em bancada de ensaio, o desempenho do sistema dosador e distribuidor de sementes em relação à variação da velocidade e da quantidade de punções utilizadas. O delineamento experimental foi em blocos casualizados arranjados em parcelas subdivididas com a parcela principal composta de 6, 9 e 12 punções e a subparcela sendo quatro rotações da roda dosadora correspondentes às velocidades de deslocamento de 4, 6, 8 e $10 \mathrm{~km} \mathrm{~h}^{-1}$.

A bancada de ensaio foi construída com cantoneiras e barras metálicas para a fixação da roda puncionadora, que incorpora os sistemas dosador e distribuidor de sementes. A roda puncionadora foi posta em movimento utilizando-se um motor elétrico e um conjunto de polias e correias para fazer a transmissão de potência. Esta bancada de testes e a roda puncionadora são mostradas na Figura 2; a regulagem da velocidade foi controlada por meio de um inversor de frequência conectado ao motor elétrico.

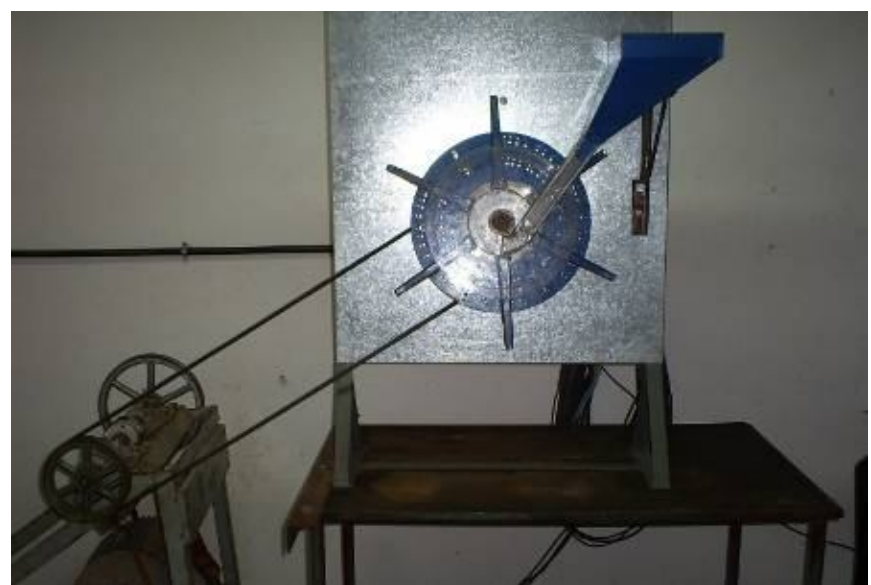

Figura 2. Bancada de testes com a roda puncionadora que incorpora os sistemas dosador e distribuidor de sementes

Para medir a velocidade rotacional do mecanismo dosador e distribuidor de sementes, utilizou-se um sensor magnético para captar pulsos a cada aproximação da punção, além de um sistema de aquisição de dados, composto de um computador portátil, um sistema de aquisição de dados (data logger) Spider 8, fabricado pela HBM, e o programa computacional CATMAN ${ }^{\circledR}$ 4.5.

Durante o experimento, foram usadas sementes de milho híbrido AG 2060, peneira C3L, conforme dados do fabricante (Agroceres). Verificou-se a quantidade de sementes dosadas e distribuídas em cada punção, através de filmagens dos ensaios da semeadora e posterior contagem das sementes. Dosagens de duas sementes por punção foram consideradas como sendo dupla, com apenas uma semente, dosagem normal, ou falha na dosagem, quando nenhuma semente foi ejetada na punção. Os resultados obtidos durante o experimento foram tabulados e submetidos à análise de variância. Para os casos em que o teste $\mathrm{F}$ foi significativo, realizou-se o teste de comparação de médias pelo teste de Tukey $(\mathrm{p}<0,05)$. Para as análises estatísticas, utilizou-se o programa computacional SAEG 9.0.

\section{RESULTADOS E DISCUSSÃO}

\section{Projeto e construção}

Definiu-se que o princípio de abertura de covas seria o mesmo utilizado por Resende (2002). Este mecanismo mostrouse preciso, confiável, possui poucas partes móveis e é de fácil construção; além do mais, este princípio revolve menos o solo e sua cobertura de palha que os sulcadores das semeadoras para sistema de plantio direto (Figura 3 ).

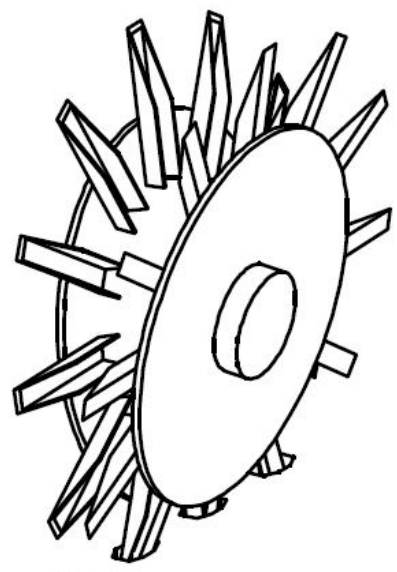

$\Phi$

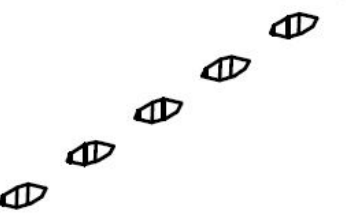

Figura 3. Sistema de abertura de covas desenvolvido por Resende (2002)

Suas rodas puncionadoras, posicionadas em "V", giram sincronizadas em razão do engrenamento entre as punções de rodas distintas; durante esse engrenamento as pontas das punções se aproximam até se tocarem e depois se afastam, até que ocorra o desengrenamento; as punções iniciam a penetração no solo quando as pontas estão se tocando; ao penetrar no solo, as punções se afastam gradativamente e durante o engrenamento essas punções formam um duto fechado, que serve para conduzir as sementes até o fundo da cova aberta.

Para variar a distância entre covas nas linhas de semeadura e,consecutivamente, a população de plantas, optou-se pela variação do número de punções nas rodas puncionadoras, por serem simples e de fácil fabricação. 
Projetou-se um dosador de sementes pneumático, a vácuo, para realizar as funções de: seleção, individualização e ejeção de sementes. Esse tipo de dosador foi selecionado pela facilidade de instalação numa das rodas puncionadoras e em razão de causar poucos danos às sementes; seu disco de sementes trabalha na posição vertical e pode ser fixado concentricamente em uma das duas rodas puncionadoras. Desta forma, eliminou-se a necessidade de sistemas de transmissão de potência. Segundo Almeida et al. (2003), esse tipo de dosador ocasiona menor dano mecânico às sementes, comparado com os sistemas de dosagem por forma, como os discos horizontais de alvéolos.

Projetaram-se discos de sementes com números variados de furos para serem usados com as combinações possíveis de número de punções, ou seja, um disco com seis furos é usado para uma configuração de seis punções instaladas nas rodas puncionadoras; assim, pode-se variar a taxa de semeadura na linha de semeadura.

Um individualizador de sementes serrilhado foi projetado para ser instalado próximo à circunferência em que se situam os furos do disco de sementes (Figura 4). O primeiro dente do serrilhado desse dispositivo toca levemente as sementes, o segundo toca as sementes com mais força, e assim sucessivamente, até o último toque, que é o mais intenso. A função desse dispositivo é eliminar as seleções de sementes múltiplas deixando somente uma presa ao disco.

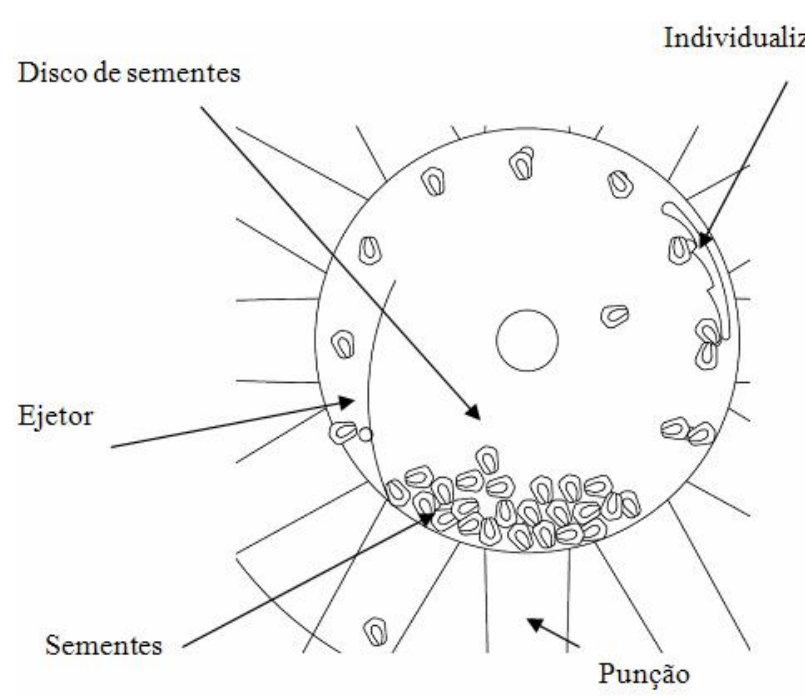

Figura 4. Layout do sistema dosador de sementes

As sementes capturadas e individualizadas eram deslocadas para dentro de um sistema distribuidor radial para serem conduzidas até o solo, por um dispositivo denominado ejetor.

O sistema de distribuição radial de sementes foi projetado para transportar as sementes desde o dosador até o fundo da cova. Este sistema, também fica fixado à roda puncionadora, incorpora o dosador de sementes e, portanto, gira na mesma velocidade dela. A parte inicial deste sistema é constituída de um canal retangular que, na realidade, é um prolongamento da punção; este canal é fechado por um disco de acrílico transparente estacionário, que facilita a visualização do transporte das sementes; a parte final é formada pelas punções de rodas distintas, que se encontram engrenadas neste momento, formando um duto fechado com paredes duplas para evitar o entupimento das punções com o solo.

Decidiu-se utilizar duas rodas, especificamente para controlar a profundidade de semeadura; ambas foram posicionadas lateralmente, próximo às rodas puncionadoras, para melhor controle da profundidade. Um mecanismo em paralelogramo foi usado para controlar o movimento vertical da unidade de semeadura; desta forma, uma linha horizontal imaginária sobre o chassis da semeadora permanece nesta orientação enquanto a máquina sobe e desce, copiando as ondulações do relevo, garantido que as punções penetrem no solo sempre fechadas para evitar o entupimento das punções. Para fechar as covas, rodas em "V" foram utilizadas comercialmente em semeadoras; o chassis é composto de duas partes ligadas por juntas rotativas ao mecanismo pantográfico; e o reservatório de sementes tem capacidade de aproximadamente $5,3 \mathrm{~kg}$ de sementes, suficiente para testes em bancada e campo.

O protótipo construído pode ser visto na Figura 5.

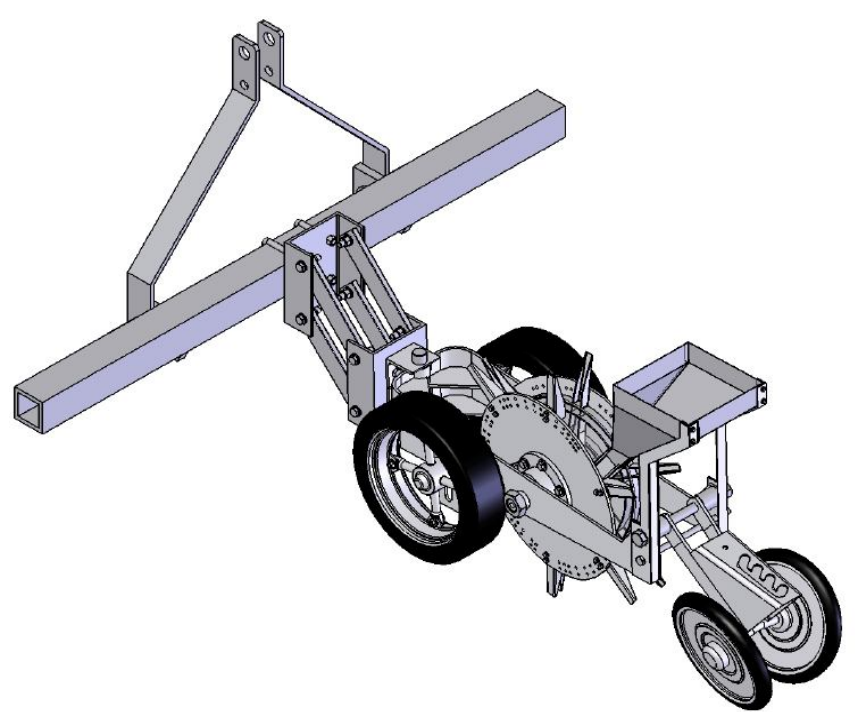

Figura 5. Perspectiva isométrica do protótipo da semeadora puncionadora

\section{Avaliação da máquina}

Análises de variância foram feitas para as porcentagens de dosagem normal (uma semente), de falhas devidas às dosagens de múltiplas sementes e à falta de dosagem. As falhas relativas às dosagens múltiplas foram restritas às duplas, ou seja, não se obtiveram dosagens triplas de sementes. Verificou-se que a interação entre o número de punções versus velocidade, apresentou diferença significativa $(\mathrm{p}<0,05)$ para as porcentagens de dosagem normal e falta de dosagem de sementes. Por outro lado, esta interação não foi significativa para a dosagem dupla.

As porcentagens médias da dosagem normal de sementes e o resultado da aplicação do teste de Tukey, são apresentados na Tabela 1. Ao avaliar o efeito da velocidade para cada uma das quantidades de punções utilizadas verifica-se, para a regulagem de seis punções, que o efeito da velocidade não foi significativo e, à medida em que a quantidade de punções foi 
aumentada o efeito da velocidade foi cada vez mais significativo. Para a regulagem de 9 punções a redução da porcentagem na dosagem normal de sementes só foi significativa para a velocidade de $10 \mathrm{~km} \mathrm{~h}^{-1}$; para 12 punções ocorreu uma diminuição significativa entre todas as velocidades, a dosagem normal de sementes reduziu de 95,08 para $75,67 \%$ sempre em que a velocidade foi aumentada de 4 para $10 \mathrm{~km} \mathrm{~h}^{-1}$.

Tabela 1. M édias de porcentagem de dosagens normais do mecanismo dosador, de acordo com o número de punções e a velocidade

\begin{tabular}{|c|c|c|c|c|c|}
\hline \multirow{2}{*}{$\begin{array}{l}\text { Número de } \\
\text { punções }\end{array}$} & \multicolumn{4}{|c|}{ Velocidade $\left(\mathrm{km} \mathrm{h}^{-1}\right)$} & \multirow{2}{*}{ Média } \\
\hline & 4 & 6 & 8 & 10 & \\
\hline 6 & $92,75 \mathrm{Aa}$ & $94,42 \mathrm{Aa}$ & $94,25 \mathrm{Aa}$ & $91,92 \mathrm{Aa}$ & 93,33 \\
\hline 9 & $94,75 \mathrm{Aa}$ & $95,00 \mathrm{Aa}$ & $92,75 \mathrm{Aa}$ & $86,42 \mathrm{Bb}$ & 92,23 \\
\hline 12 & $95,08 \mathrm{Aa}$ & $90,42 \mathrm{Bb}$ & $83,17 \mathrm{Cb}$ & $75,67 \mathrm{DC}$ & 86,08 \\
\hline Média & 94,19 & 93,28 & 90,06 & 84,67 & 90,55 \\
\hline
\end{tabular}

Nota: Médias seguidas de mesmas letras maiúscula na linha e de mesmas letras minúsculas na coluna, não diferem estatisticamente entre si, pelo teste de Tukey a $5 \%$ de probabilidade

Obtiveram-se os melhores resultados quando o protótipo trabalhou na menor velocidade $\left(4 \mathrm{~km} \mathrm{~h}^{-1}\right)$, e então se obteve uma média de 94,19\% na dosagem normal de sementes ou, com a menor quantidade de punções (seis), ao se encontrar uma média de 93,33\% na dosagem normal de sementes. O valor máximo na dosagem normal de sementes foi de $95,08 \%$ e o valor médio geral, de $90,55 \%$.

As porcentagens médias da falta de dosagem de sementes e o resultado da aplicação do teste de Tukey são apresentados na Tabela 2; ao avaliar o efeito da velocidade para cada uma das quantidades de punções utilizadas, observou-se comportamento similar ao da dosagem normal de sementes, porém com aumento deste índice. Pode-se verificar, para a regulagem de seis punções, que o efeito da velocidade não foi significativo. Na medida em que a quantidade de punções foi aumentada o efeito da velocidade também foi cada vez mais significativo; para a regulagem de 9 punções o aumento da porcentagem na falta de dosagem de sementes só foi significativo para a velocidade de $10 \mathrm{~km} \mathrm{~h}^{-1}$; para 12 punções ocorreu um aumento significativo entre todas as velocidades e a falta de dosagem de sementes aumentou de 3,53 para $25,77 \%$ sempre que a velocidade foi aumentada de 4 para $10 \mathrm{~km} \mathrm{~h}^{-1}$.

Os melhores resultados foram obtidos quando o protótipo trabalhou na menor velocidade $\left(4 \mathrm{~km} \mathrm{~h}^{-1}\right)$, e se obteve, então, a média de $2,58 \%$ na falta de dosagem de sementes, ou com a

Tabela 2. Médias de porcentagem de falha de dosagem devido à falta de dosagem de sementes do mecanismo dosador, de acordo com o número de punções e da velocidade

\begin{tabular}{cccccc}
\hline Número de & \multicolumn{4}{c}{ Velocidade $\left(\mathbf{k m ~ h}^{\mathbf{- 1}}\right)$} & \multirow{2}{*}{ Média } \\
\cline { 2 - 5 } punções & $\mathbf{4}$ & $\mathbf{6}$ & $\mathbf{8}$ & $\mathbf{1 0}$ & \\
6 & $2,01 \mathrm{Aa}$ & $1,59 \mathrm{Aa}$ & $2,68 \mathrm{Aa}$ & $6,26 \mathrm{Aa}$ & 3,14 \\
9 & $2,19 \mathrm{Aa}$ & $2,76 \mathrm{Aa}$ & $5,99 \mathrm{Aa}$ & $13,10 \mathrm{Bb}$ & 6,01 \\
12 & $3,53 \mathrm{Aa}$ & $9,11 \mathrm{Bb}$ & $17,06 \mathrm{Cb}$ & $25,77 \mathrm{Dc}$ & 13,87 \\
\hline Média & 2,58 & 4,49 & 8,58 & 15,04 & 7,67 \\
\hline
\end{tabular}

Nota: Médias seguidas de mesmas letras maiúscula na linha e de mesmas letras minúsculas na coluna, não diferem estatisticamente entre si, pelo teste de Tukey a $5 \%$ de probabilidade menor quantidade de punções (seis), quando se obteve a média de $3,14 \%$ na falta de dosagem.

Uma análise do efeito do número de punções em cada velocidade para avaliar a dosagem normal e a falta de dosagem de sementes, mostra que o desempenho do protótipo piorou quando a quantidade de punções aumentou. Esta queda de desempenho não foi significativa estatisticamente a nível de $5 \%$ de probabilidade para $4 \mathrm{~km} \mathrm{~h}^{-1}$; entretanto, na medida em que a velocidade aumentou, o desempenho do protótipo piorou significativamente, reduzindo a porcentagem de dosagens normais e aumentando a porcentagem de falhas na dosagem de sementes. Este problema pode ser explicado por uma provável redução do vácuo nos furos dos discos de sementes, o que pode ter acontecido pois, quanto maior a quantidade de punções utilizadas maior é também a quantidade de furos nos discos de sementes e, consequentemente, maior o fluxo de ar que passa pelos canais internos da roda puncionadora. Desta forma, aumenta-se a perda de carga no escoamento do ar, reduzindo a pressão nos furos dos discos de sementes.

As porcentagens médias de dosagem dupla de sementes e o resultado da aplicação do teste de Tukey, são apresentados na Tabela 3. Verificou-se que a interação entre o número de punções $X$ velocidade, não mostrou diferença significativa ( $p$ $<0,05)$ para a dosagem dupla de sementes. A média de falha devida à dosagem de sementes duplas diminuiu significativamente, tanto com o aumento da velocidade quanto com o aumento do número de punções instaladas nas rodas puncionadoras, comportamento este oposto ao das falhas em virtude da falta de dosagem da semente.

Tabela 3. Médias de percentagem de falha de dosagem em razão das dosagens duplas do mecanismo dosador, de acordo com o número de punções e da velocidade

\begin{tabular}{|c|c|c|c|c|c|}
\hline \multirow{2}{*}{$\begin{array}{l}\text { Número de } \\
\text { punções }\end{array}$} & \multicolumn{4}{|c|}{ Velocidade $\left(\mathrm{km} \mathrm{h}^{-1}\right)$} & \multirow{2}{*}{ Média } \\
\hline & 4 & 6 & 8 & 10 & \\
\hline 6 & 5,25 & 4,00 & 3,08 & 1,92 & $3,56 a$ \\
\hline 9 & 3,08 & 2,25 & 1,33 & 0,92 & $1,90 \mathrm{~b}$ \\
\hline 12 & 1,42 & 0,67 & 0,58 & 0,33 & $0,75 c$ \\
\hline Média & $3,25 \mathrm{~A}$ & $2,30 \mathrm{AB}$ & $1,67 \mathrm{BC}$ & $1,06 \mathrm{C}$ & 2,07 \\
\hline
\end{tabular}

Nota: Médias seguidas de mesmas letras maiúscula na linha e de mesmas letras minúsculas na coluna, não diferem estatisticamente entre si, pelo teste de Tukey a 5\% de probabilidade

A redução do número médio de dosagem dupla de sementes com o aumento da velocidade, pode ser explicada pela ação do individualizador pois, quanto mais elevada for a velocidade da roda puncionadora, mais fortes serão os toques das sementes com o serrilhado do individualizador.

A redução do número médio de dosagem dupla de sementes com o aumento da quantidade de punções instaladas nas rodas puncionadoras, também pode ser explicada por uma provável redução do vácuo nos furos dos discos de sementes causada pelo aumento da perda de carga, citado anteriormente. Todas as sementes foram dosadas abaixo de uma linha que representava o solo, provando que o sistema de distribuição de sementes foi eficiente, mesmo para altas velocidades de trabalho.

Bonnin (2000) avaliou três protótipos de semeadoras puncionadoras para semeadura direta de milho, as quais 
seguiam o mesmo princípio desenvolvido por Shaw \& Kromer (1987) com mecanismos de dosagem comerciais diferenciados; o primeiro, com dosador pneumático; o segundo, de dedos preensores e o terceiro do tipo colher. Nos ensaios em laboratório os melhores resultados foram encontrados no mecanismo dosador pneumático, sendo que 96,1, 96,4 e 95,4\% das dosagens foram normais nas velocidades de 5,4; 7,2 e 9,0 $\mathrm{km} \mathrm{h}^{-1}$, respectivamente. Esses resultados são semelhantes aos encontrados no presente trabalho no experimento em que se utilizaram 6 punções. Nota-se que melhorias ou novos mecanismos dosadores especializados são necessários para a evolução de semeadoras puncionadoras.

\section{ConclusõEs}

1. O sistema de abertura de covas por meio de rodas posicionadas em "V" e dosadores acoplados à roda é uma solução viável para o sistema de semeadura pontual de milho.

2. O aumento da velocidade de deslocamento provocou o aumento do número de falhas relativas à falta de dosagem para 9 e 12 punções, além do aumento do número de punções para velocidade acima de $6 \mathrm{~km} \mathrm{~h}^{-1}$.

3. As falhas devidas à dosagem dupla de sementes indicaram comportamento oposto ao das falhas devidas às faltas.

4. O melhor desempenho em relação à dosagem normal de sementes ocorreu quando do uso de 6 punções para velocidades de até $10 \mathrm{~km} \mathrm{~h}^{-1}$ ou para $4 \mathrm{~km} \mathrm{~h}^{-1}$ utilizando-se 6,9 ou 12 punções.

\section{LITERATURA CITADA}

Adekoya, L. O.; Buchele W. F. A precision punch planter for use in tilled and untilled soils. Journal of Agricultural Engineering Research, v.37, p.171-178, 1987.

Almeida, R. A.; Barcellos, L. C.; Ximenes, P. A. Danos mecânicos ocasionados por sistemas dosadores de sementes. Pesquisa Agropecuária Tropical, v.33, p.17-22, 2003.
Aratani, R. G.; Maria, I. C.; Castro, O. M.; Peche Filho, A.; Duarte, A. P.; Kanthack, R. A. D. Desempenho de semeadorasadubadoras de soja em Latossolo Vermelho muito argiloso com palha intacta de milho. Revista Brasileira de Engenharia Agrícola e Ambiental, v.10, p.517-522, 2006.

Bonnin; J. J. Avaliação de protótipos de semeadoras de covas para semeadura direta. Piracicaba: ESALQ/USP, 2000. 84p. Dissertação Mestrado

Garcia, L. C.; Jasper, R.; Jasper, M.; Ornari,A. J.; Blum, J. Influência da velocidade de deslocamento na semeadura do milho. Engenharia Agrícola, v.26, p. 520-527, 2006.

Heinemann Júnior, W. H.; Cary, J. W.; Dilworth, A. E. Experimental machine for autodibble planting. Transactions of the ASAE, v.16, p.656-659, 1973.

Jafari, J. V.; Fornstrom, K. J. A precision punch-planter for sugar beets. Transactions of the ASAE, v.15, p.569-571, 1972.

Kurachi, S. A. H.; Costa, J. A. S.; Bernardi, J. A.; Coelho, J. L. O.; Silveira, G. M. Avaliação tecnológica de semeadoras e/ ou adubadoras. Tratamento de dados de ensaios e regularidade de distribuição longitudinal de sementes. Bragantia, v.48, p.249-262, 1989.

Mahl, D.; Gamer, C. A.; Benez, S. H.; Furlani, C. E. A.; Silva, A. R. B. Demanda energética e eficiência da distribuição de sementes de milho sob variação de velocidade e condição de solo. Engenharia Agrícola, v.24, p.150-157, 2004.

Molin, J. P.; Bashford, K.; von Bargen, L. I. Leviticus. Design and Evaluation of a punch planter for no-till systems. Transactions of the ASAE, v.41, p.307-314, 1998.

Pahl, G.; Beitz, W. Engineering design: A systematic approach. 2.ed. London: Springer Verlag, 1996. 579p.

Palhares, M. Distribuição e população de plantas e produtividade de grãos de milho. Piracicaba: ESALQ/USP, 2003. 107p. Dissertação Mestrado

Pereira, F. R. da S.; Cruz, S. C. S.; Albuquerque, A. W.; Santos, J. R.; Silva, E. T. Arranjo espacial de plantas de milho em sistema plantio direto. Revista Brasileira de Engenharia Agrícola e Ambiental, v.12, p.69-74, 2008.

Resende. R. C. Design of a novel punch planter capable of producing equidistant seed spacing of irregular shaped seeds. Silsoe: Cranfield University, 2002. 229p. Tese Doutorado 